\title{
Improving clean and healthy living behaviour through snakes and ladders board game among school children
}

\author{
*Lita Heni Kusumawardani ${ }^{1}$, Etty Rekawati ${ }^{2}$, Poppy Fitriyani ${ }^{2}$, Yunita Sari Dian Putu Ni Luh ${ }^{2}$
}

Sri Lanka Journal of Child Health, 2020; 49(4): 341-346

\begin{abstract}
Introduction: Community nurses have a strategic role in improving clean and healthy living behaviour by providing health education to the community. Play therapy is one of the nursing interventions that can be a method of health education in school children.
\end{abstract}

Objective: To determine the effect of snakes and ladders board game with peers modelling approach in improving clean and healthy living behaviour of school children.

Method: The design is quasi experimental pretest post-test with control group. Calculated sample size was 126 school chidren 6-12 years old who had a problem of lack of clean and healthy living behaviour. The researchers used simulation of snakes and ladders board game in four sessions over 1 month, staging each session for 45 minutes. Data collection tool was a questionnaire consisting of variable knowledge, attitudes, and clean and healthy living behaviour skills of school-age children. Data was analysed using the paired t-test.

Results: Parental education levels were low in $56 \%$ and parental incomes were low in $58 \%$. About $75 \%$ children had a diarrhoeal disease in past 3 months. Handwashing facilities, clean water sources, and healthy latrines were readily available in $70.5 \%$. Knowledge about clean and healthy living behaviour children increased from $44.7 \%$ to $60.9 \%$, child's attitude about clean and healthy living behaviour increased from $43.8 \%$ to $59.5 \%$, skills of children of clean and healthy living behaviour increased from $41.2 \%$ to $55.7 \%$ after engaging in simulation

\footnotetext{
${ }^{1}$ Universitas Jenderal Soedirman, Indonesia

${ }^{2}$ Universitas Indonesia, Indonesia

*Correspondence:

litahenikusumawardani@unsoed.ac.id

orcid.org/ 0000-0002-5293-2139
}

(Received on 21 December 2019: Accepted after revision on 24 January 2020)

The authors declare that there are no conflicts of interest

Personal funding was used for the project.

Open Access Article published under the Creative

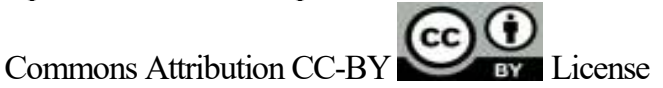

of snakes and ladders board game. Alternatively, in the control group, there was no significant change in values of knowledge, attitude, and skills variables.

Conclusions: Simulation of snakes and ladders board game significantly increases knowledge, attitudes, and skills of clean and healthy living behaviour in school children.

DOI: http://dx.doi.org/10.4038/sljch.v49i4.9265

(Key words: School children, snakes and ladders board game, clean and healthy living behaviour)

\section{Introduction}

As understanding of healthy behaviour is not high among school children, they are exposed to the risk of health problems ${ }^{1}$. The risks may be biological, behavioural and environmental ${ }^{2}$. The government has tried to change the behaviour of the community, including school children, and improve health status through the clean and healthy living behaviour development programmes which include clean and healthy living behaviour management officers, making guidance book of clean and healthy living behaviour programme, and campaign or socialization of clean and healthy living behaviour ${ }^{3}$. Community nurses play a strategic role in improving clean and healthy living behaviour by providing health education to the community ${ }^{4}$. Play therapy is a nursing intervention that can be a method of health education in school children. Play therapy techniques include educational games, role playing, storytelling, drawing, music, pets and dolls ${ }^{5}$. One of the educative games that can be used is the snakes and ladders board game.

Ghimire showed that using the snakes and ladder board game effectively in school children improves knowledge of balanced nutrition, including balanced nutrition components, importance of balanced nutrition, and consequences of unbalanced nutritional intake ${ }^{6}$. Ejike, et al developed an innovative educational game 'worms and ladders' to prevent worm disease in school children ${ }^{7}$. Knowledge about transmission of worm disease, clean water use, and worm disease prevention behaviour 
increased after educational 'worms and ladders' performed on school children?.

The role of peers contributes greatly in changing the behaviour of children considering that many school children interact with their peers. Studies indicate an improvement in mean scores of knowledge, attitudes, and skills related to clean and healthy living behaviour after peer educators conducted sessions in the intervention group $^{8.9}$. In addition, there is a significant decrease in incidence of worms after peers educators conducted sessions in the intervention group so that peers have a role in improving knowledge, attitude, and skills of school children ${ }^{10,11}$. Therefore, the researcher applied an educational game of snakes and ladder using peers modelling approach as an intervention of clean and healthy living behaviour in school children in the community.

\section{Objectives}

To determine the effect of snakes and ladders board game with peers modelling approach to improve clean and healthy living behaviour of school children.

\section{Method}

Design: Quasi experimental design pre-test post-test with control group.

Population and study setting: Sample size was 126 children of whom 64 were allotted to intervention group and 62 to the control group. Multistage random sampling was used to determine location and schools where study was to be carried out, whilst the study subjects were determined by simple random sampling. Curug 3 elementary school was selected as intervention group and Curug 4 elementary school as the control group.

Variables: Variables in this study were knowledge, attitudes, and skills of school children clean and healthy living behaviour. The questionnaire used a modification of previous studies. Analysis of data using data processing programme is displayed in percentage changes in knowledge, attitudes, and skills of clean and healthy living behaviour.

Data collection: The data collection tool was a questionnaire based on guidelines of past research and guidance from Indonesian Directorate General of Disease Control and Environmental Health and Health Ministry ${ }^{12,13}$. Results of validity and reliability testing showed the instrument to be valid and reliable as a measure of clean and healthy living behaviour. Further, an observation sheet was used to identify availability of handwashing facilities, healthy latrines, and clean water sources.

Data analysis: Univariate and bivariate analysis were used. Univariate analysis was used to describe the characteristics of each variable examined in this study. Bivariate test was used for the numerical data on the comparative paired two groups with a normal distribution of data using paired t-test.

Ethical Aspects: This study applied ethics in research to each respondent and respected human dignity, non-maleficence, and justice. It has been approved by the Faculty of Medicine and Health Sciences Ethics Committee.

\section{Results}

The parental education levels were low in $56 \%$ and the parental incomes were low in 58\%. Around $75 \%$ of children had experienced a diarrhoeal disease in the previous 3 months. Handwashing facilities, clean water sources, and healthy latrines were readily available in $70.5 \%$. Results of the paired t-test of knowledge, attitude, and skills variables on school children in Curug 3 and 4 elementary schools in 2017 are shown in Table 1.

Table 1: Results of the paired t-test of knowledge, attitude, and skills variables on school children in Curug 3 and 4 elementary schools in $2017(n=126)$

\begin{tabular}{|c|c|c|c|c|c|c|}
\hline \multirow{3}{*}{ Variable } & \multicolumn{6}{|c|}{ Intervention Group $(n=64)$} \\
\hline & \multicolumn{2}{|c|}{ Before } & \multicolumn{2}{|c|}{ After } & \multirow[b]{2}{*}{ Difference in mean } & \multirow[b]{2}{*}{ p value } \\
\hline & Mean & SD & Mean & SD & & \\
\hline Knowledge & 7.52 & 1.297 & 9.94 & 1.524 & 2.42 & 0.003 \\
\hline Attitude & 30.78 & 2.889 & 32.59 & 3.589 & 1,81 & 0.004 \\
\hline Skills & 27.54 & 2.632 & 28.98 & 2.701 & 1,46 & 0.007 \\
\hline \multirow{3}{*}{ Variable } & \multicolumn{6}{|c|}{ Control Group $(n=62)$} \\
\hline & \multicolumn{2}{|c|}{ Before } & \multicolumn{2}{|c|}{ After } & & \\
\hline & Mean & SD & Mean & SD & Difference in mean & p value \\
\hline Knowledge & 7.64 & 1.301 & 8.02 & 1.328 & 0.38 & 0.111 \\
\hline Attitude & 31.48 & 2.902 & 32.19 & 3.236 & 0.71 & 0.126 \\
\hline Skills & 28.03 & 2.762 & 28.72 & 2.872 & 0.69 & 0.108 \\
\hline
\end{tabular}


The result of analysing the knowledge, attitude, and skills variables shows a significant change in the levels of each variable before and after engaging in simulation of snakes and ladders board game. Alternatively, in the control group, there was no significant change in the mean values of the knowledge, attitude, and skills variables. Distribution of knowledge, attitudes, and skills of clean and healthy living behaviour in school children before and after intervention is shown in Figure 1.



Figure 1: Distribution of the paired t-test of knowledge, attitude and skills variables in school children in Curug 3 and Curug 4 elementary schools in $2017(n=126)$

Based on the data obtained from Figure 1, knowledge about clean and healthy living behaviour of children increased from $44.7 \%$ to $60.9 \%$, the child's attitude about clean and healthy living behaviour increased from 43,8\% to $59.5 \%$ and the skills of children of clean and healthy living behaviour increased from $41.2 \%$ to $55.7 \%$.

\section{Discussion}

Bivariate analysis showed that snakes and ladders board game affected knowledge, attitudes, and skills of clean and healthy living behaviour in school children. The snakes and ladders game is one of cooperative play and is a traditional game that is cheap, easy to make, and commonly performed by children with effective learning strategy through active, creative, effective and fun approach for school children $^{14,15}$ : Educational Game Tool snakes and ladders can be given to elementary school children because the game is easy to play, children learn to work together and being fair play, socialize with peers, as well as playing while learning. SCL play therapy (Snakes, Cards and Ladders) effectively improves handwashing behaviour in school children ${ }^{16}$.
Snakes and ladders is a game that provides a stimulus to some of the human senses. When playing a snakes and ladders game, the used sense besides the eyes are the ears. School children read the questions or commands and see the pictures contained in the snakes and ladders board. In addition, players read the answer sheets that match the obtained commands or questions to validate the correctness of the player's answers and provide explanations to school children about clean and healthy living behaviour materials. The desired hope is that school children become interested to learn the illustrated and written information in the snakes and ladders game so that there is an increase in knowledge in school children about clean and healthy living behaviour material.

Health education by snakes and ladders simulation method is expected to build a trust so that school children have a positive attitude to healthy behaviour. School children who are behaving negatively can change their attitudes to be positive after the intervention is given that is affected by: the giving of information about 
clean and healthy living behaviour that is delivered clearly so as to influence the emotions of school children. Attitude statements given by the researchers to school children should also be able to stimulate the confidence of school children.

Changes in behaviour require a change of knowledge, a change of attitude, and a change of action, a process of behavior adaptation through the stages of input, control processes, effector, and output ${ }^{17}$. The input is given in the form of clean and healthy living behaviour health education with snakes and ladder simulation game method, then processed through regulator system (limbic system produces positive coping) and cognator (learning process through the media of simulation of snakes and ladders).

The researchers make modifications by entering the brain gym material into a snakes and ladders game as a form of cognitive stimulation for school children. It aims to increase the motivation in clean and healthy living, especially in physical activity. This is in accordance with the statement that the brain gym effectively improves the child's motivation for the physical activity ${ }^{18}$. The brain gym is an exercise programme to build brain power as a form of stimulation for sensory as well as motor activity in the body, especially in school children $^{19}$.

Some of the demonstration activities on clean and healthy living behaviour practices such as hand washing, vegetable and fruit consumption, and physical activity in daily life are taught by the researcher through the snakes and ladders game $^{20}$. Clean and healthy living behaviour demonstration practices are conducted together with school children, parents, and teachers. The researcher needs to emphasize to the parents and teachers that all forms of their behaviour in daily life will be imitated by the child and it will form a behavioural pattern used by the child so that the researcher always reminds the parents and teachers that it is important to wash their hands before preparing food, before and after eating, after holding dirty objects, and after doing activity outside the home. Parents and teachers are encouraged to wash hands, consume vegetables and fruit, and encourage children to exercise regularly with light movements at home and outdoors ${ }^{21}$.

After all the learning and training sessions have been completed, the researchers monitor the implementation of clean and healthy living behaviour through booklet media. The researchers need to make modifications through a booklet where there is a health information that can be read at any time by school children, teachers, and family and contains records of daily clean and healthy living behaviour developments which are monitored by parents. The simulation game method becomes one of the stimuli that can be used in giving the child the health education that is interesting for school children. This game method is chosen because the learning process will be more active and more fun if combined with the game $\mathrm{e}^{22,23}$.

The snakes and ladders game is one that is widely known by children all over the world ${ }^{14}$. A study related to the usage of the snakes and ladders game principle was also conducted by Ejike, Oluwole, \& Mogaji ${ }^{7}$. They modified the snakes and ladders game by using the worms and ladders board game to improve the prevention behaviour of worm disease in school-age children ${ }^{7}$. The results showed that health education using game board of worms and ladders can improve knowledge, attitude, practice the worm disease prevention and reduce worm disease in school children. Lambie, Lindberg, \& Ruskin also used the snakes and ladders game in identifying parental role relationships to the emotional abilities of children aged 4-7 years ${ }^{24}$. The usage of snakes and ladder game media can increase knowledge and attitude in the selection of healthy snacks in school children ${ }^{16}$. Some results of this study indicate that snakes and ladders game can be developed to improve clean and healthy living behaviour in school children.

\section{Conclusions}

Simulation of snakes and ladders board game significantly increases knowledge, attitudes, and skills of clean and healthy living behaviour in school children.

\section{Acknowledgments}

We acknowledge all parties who supported this research, especially the students of Curug 3 Elementary School and Curug 4 Elementary School, who were willing research respondents.

\section{References}

1. RI Ministry of Health. Health in the Framework of Sustainable Development Goals (SDGs). Rakorpop Ministry of Health Republic of Indonesia [Internet]. 2015; (97): 24. Available from: http://www.pusat2.litbang.depkes.go.id /pusat2_v1/wpcontent/uploads/2015/12 /SDGs-Ditjen-BGKIA.pdf 
2. Allender JA, Rector C, Warner KD. Community \& public health nursing: promoting the public's health. 2014.

3. RI Ministry of Health. Ministry of Health of the Republic of Indonesia. 2013; Available from:

http://www.depkes.go.id/article/view/2 383/diabetes-melitus-penyebab-

kematian-nomor-6-di-dunia-kemenkessolutions-solution-cerdik-throughposbindu.html

4. Marcia Stanhope and Jeanette Lancaster. Public Health Nursing: Population-Centered Health Care in the Community. 9th ed. Elsevier Health Sciences; 2015. 1120 pages.

5. Tilbrook A, Dwyer T, Reid-Searl K, Parson JA. A review of the literature The use of interactive puppet simulation in nursing education and children's healthcare. Nurse Education in Practice 2017; 22: 73-9.

https://doi.org/10.1016/j.nepr.2016.12. 001

PMid: 28024279

6. Ghimire S. A study to assess the effectiveness of game-based learning on knowledge regarding the healthy dietary pattern among school children in selected government schools, Bengaluru. Asian Journal of Nursing Education and Research 2016; 6(1): 133-7.

https://doi.org/10.5958/23492996.2016 .00026 .4

7. Ejike CU, Oluwole AS, Mogaji HO. Development and testing of Schisto and Ladders TM, an innovative health educational game for control of schistosomiasis in schoolchildren. BMC Research Notes 2017; 10: 236. https://doi.org/10.1186/s13104-0172545-5

PMid: 28659195 PMCid:

PMC5490240

8. Haleem A, Khan MK, Sufia S, Chaudhry S, Siddiqui MI, Khan AA. The role of repetition and reinforcement in school-based oral health education-a cluster randomized controlled trial. BMC Public Health 2016; 16: 2. https://doi.org/10.1186/s12889-015-

2676-3

PMid: 26728002 PMCid:

PMC4700643

9. Kusumawardani LH, Rekawati E, Fitriyani PF. Improving diarrhoea and clean and healthy living behaviour (PHBS) through collaboration sociodramatic play (Co-Boarding) in school age children. Sri Lanka Journal of Child Health 2019; 48(3): 240. https://doi.org/10.4038/sljch.v48i3.875 9

10. Shrestha RM, Miyaguchi M, Shibanuma A, Khanal A, Yasuoka J, Jimba M. A school health project can improve the health status of school children in Nepal. PLoS One 2016; 11(11): 1-17.

https://doi.org/10.1371/journal.pone.01 66001

PMid: 27812190 PMCid:

PMC5094771

11. Kusumawardani LH, Mulyono S, Fitriyani P. Improving diarrhoeal preventive behaviour through therapeutic sociodramatic play in school-aged children. Global Nursing 2018; 17(3).

https://doi.org/10.6018/eglobal.17.3.30 4701

12. Wahyuni S. Effect of behavior modification with modeling techniques on hand washing behavior in schoolage children in Sukowono District, Jember Regency. University of Indonesia; 2016

13. Demberere T, Chidziya T, Ncozana T, Manyeruke N. Knowledge and practices regarding water, sanitation and hygiene (WASH) among mothers of infections in Mawabeni, Umzingwane District of Zimbabwe. Physics and Chemistry of the Earth 2016; 92: 119-24. https://doi.org/10.1016/j.pce.2015.09.0 13

14. Reid R, Niekerk J Van, Elizabeth P, Africa S. Snakes and ladders for digital natives: information security education for the youth. Information Management and Computer Security 2014; 22(2): 179-90. 
https://doi.org/10.1108/IMCS-092013-0063

15. Samsuni S, Mulyono S, Wiarsih W, Heni Kusumawardani L. Photovoice interactive media improves the personal hygiene of teenage students at pesantren school in Tangerang. Enfermeria Clinica 2019; 29 Suppl 2: 681-6.

https://doi.org/10.1016/j.enfcli.2019.04 .104

PMid: 31331731

16. Kurniawati D, Rohmana DY, Juliningrum PP. The effect of Snakes and Ladders Game on knowledge and attitudes in facing menarche in Pringgowirawan Elementary School 01 Sumberbaru Jember Regency 2017; 5 (1). Available from:

https://jurnal.unej.ac.id/index.php/JPK/ article/view/4066

17. Zhang C, Mosa AJ, Hayward AS, Matthews SA. Promoting clean hands among children in Uganda: A schoolbased intervention using 'tippy-taps.' Public Health 2013; 127 (6): 586-9. https://doi.org/10.1016/j.puhe.2012.10. 020

PMid: $23267769 \quad$ PMCid: PMC4065016

18. Dodson S, Klassen KM, McDonald K, Millard T, Osborne RH, Battersby MW, et al. HealthMap: A cluster of randomized trials of interactive health plans and self-management support for preventing coronary heart disease in people with HIV. BMC Infectious Diseases 2016; 16(1): 1-12. https://doi.org/10.1186/s12879-0161422-5

PMid: 26945746 PMCid:

PMC4779564

19. Pojednic R, Peabody S, Carson S, Kennedy M, Bevans K, Phillips EM. The effect of before school physical activity on child development: A study protocol to evaluate the Build Our Kids Success (BOKS) Program. Contemporary Clinical Trials 2016; 49: $103-8$. https://doi.org/10.1016/j.cct.2016.06.0 09

PMid: 27339866
20. Meiklejohn S, Ryan L, Palermo C. A systematic review of the impact of Multi-Strategy Nutrition Education Programs on health and nutrition of adolescents. Journal of Nutrition Education and Behaviour 2016; 48 (9): 631-46.e1.

https://doi.org/10.1016/j.jneb.2016.07. 015

PMid: 27720105

21. Rosi A, Scazzina F, Ingrosso L, Morandi A, Del Rio D, Sanna A. The "5 a day" game: a nutritional intervention utilising innovative methodologies with primary school children. International Journal of Food, Sciences and Nutrition 2015; 66(6):713-7.

https://doi.org/10.3109/09637486.2015 .1077793

PMid: 6307556

22. Niemi K. "I will send badass viruses." Peer threats and the interplay of pretend frames in a classroom dispute. Journal of Pragmatics 2014; 66:10621. https://doi.org/10.1016/j.pragma.2014. 02.012

23. Kusumawardani LH, Mulyono S, Fitriyani P. Parental knowledge influenced the effectiveness of therapeutic sociodramatic play on diarrhoeal preventive behaviour in school-age children. Comprehensive Child and Adolescent Nursing 2019; 42(sup1): 122-34.

https://doi.org/10.1080/24694193.2019 .1578433

PMid: 31192736

24. Lambie JA, Lindberg A, Ruskin A. The role of maternal emotional validation and invalidation on children's emotional awareness. Merrill Palmer Quarterly 2016; 62(2):129-57.

https://doi.org/10.13110/merrpalmquar 1982.62.2.0129 